\title{
DIGITAL ENG
}

Semana Online Científica de Engenharia

\section{PLANEJAMENTO E CONTROLE DA MANUTENÇÃO: ANÁLISE DO PLANO ANUAL DE MANUTENÇÃO PREVENTIVA DA COZINHA DE UMA EMPRESA OFFSHORE}

\author{
Rayza Fernanda Freitas Campista ${ }^{1}$; Matheus Ferreira Rangel da Rocha ${ }^{2}$; Maykon de \\ Souza $a^{3}$ \\ Estudante do curso de Engenharia de Produção; e-mail: rayzaffc@yahoo.com.br ${ }^{1}$ \\ Estudante do curso de Engenharia de Produção ${ }^{2}$ \\ Professor do curso de Engenharia de Produção ${ }^{3}$
}

\begin{abstract}
RESUMO
A manutenção é um dos setores em crescimento no ambiente industrial. Com esse crescimento, dá-se muita importância para a Manutenção Preventiva que é aquela que visa às ações antes da quebra de uma máquina. A quebra produz tempos de parada de produção, o que é totalmente inviável no ambiente competitivo das indústrias no cenário atual. Durante muito tempo houve preocupação somente com a produção, mas agora começa a haver uma consciência de que a manutenção de máquinas e equipamentos é uma função estratégica dentro das empresas, pois a manutenção garante a confiabilidade e manutenabilidade do processo produtivo. Dessa maneira, o presente trabalho tem como objetivo efetivar uma análise do plano anual de manutenção preventiva já instalado na unidade operacional offshore, visando a encontrar o melhor caminho de superar os gargalos existentes na manutenção a bordo, além de planejar e otimizar a mão de obra da manutenção. Tendo o foco na análise dos dados já existentes, nas metodologias e estratégias já instaladas, o estudo se desenvolverá por forma de uma análise de caso. Com isso, pretende encontrar as respostas necessárias para agregar valor não só para que toda
\end{abstract}




\section{DIGITAL ENG}

Semana Online Científica de Engenharia

25 a 27 de Outubro de 2021

população acadêmica tenha acesso aos resultados, mas que também gere valor no planejamento e na gestão da manutenção da empresa, objetivando a otimização dos resultados. Caracteriza-se como uma pesquisa exploratória; descritiva e explicativa. No que diz respeito aos meios, é documental e bibliográfica. A escolha do tema se justifica a partir da grande importância de se ter um bom planejamento e controle de manutenção dentro da organização, com o propósito de evitar falhas e desperdícios, prevenindo paradas não programadas e até mesmo evitando acidentes. Os dados usados para essa análise foram obtidos através do Plano Anual de Manutenção Preventiva da cozinha da empresa, que será objeto de estudo deste trabalho. A partir dos dados recebidos, será analisado o desempenho através de KPI que ajudarão a criar a possibilidade de um plano de sugestão para melhorar a qualidade das tomadas de decisões. Com base na literatura e dados cedidos pela empresa, os dados levantados serão confrontados, a fim de encontrar possíveis pontos de melhoria no plano estudado.

Palavras-chave: Manutenção Preventiva; Gestão de Manutenção; Pano anual de Manutenção.

\section{INTRODUÇÃO}

Tendo em vista o fecundo desenvolvimento tecnológico dos últimos anos, a par com um mercado cada vez mais acirrado e competitivo, observa-se que a indústria vem sofrendo inúmeras mudanças, perdendo alguns traços que a caracterizavam, adicionando outros, é bem verdade, e tudo isso como mecanismo adaptativo e cumulativo. Ou seja, ela, a indústria, segue transformando a cultura e sua estratégia, na perspectiva de melhor otimizar a produtividade e fazer perdurar seus produtos por meio da preservação, isto é, da manutenção.

Sobre esse assunto de criar condições favoráveis para o desenvolvimento de algum produto, quer dizer, para sua manutenção, Fogliato, F. (2009) entende que tais manutenções devem ser realizadas com o objetivo de prevenir falhas ou de restaurar o 


\section{DIGITAL ENG}

Semana Online Científica de Engenharia

25 a 27 de Outubro de 2021

sistema a seu estado operante, caso haja a ocorrência de alguma falha. Para ele, portanto, o objetivo principal da manutenção é manter e melhorar a confiabilidade e a regularidade de operação do sistema produtivo.

Kardec e Nascif (2013), por sua vez, argumentam que se a manutenção até então era percebida como prejuízo financeiro, hoje ela é interpretada como um ativo, tendo como ponto central a redução dos custos de produção ou serviços, redução essa alinhada às melhorias dos processos, bem como à qualidade da produção o que, consequentemente, levaria a um menor número de quebras de equipamentos, maior produtividade, melhoria nos produtos, advindo daí empresas mais competitivas e, sobretudo, um elevado grau de satisfação do cliente. Como resultado de todo esse desempenho, sucederia uma elevação do lucro, com a possibilidade de aquisição de novos maquinários e, até mesmo, com aumento do quadro de funcionários.

Contextualizando a manutenção no cenário offshore, eleva-se a importância de sua precisão e confiabilidade, pois a bordo das plataformas, os recursos são limitados, devido à dependência de uma complexa logística de materiais, cujos espaços são limitados para armazenamento de sobressalentes. Observa-se que tais impactos considerados extremos são devido às condições climáticas e às condições operacionais.

Diante do exposto, conclui-se que se deve observar a importância de um plano anual de manutenção preventiva bem elaborado e preciso, porquanto, segundo os autores citados, a manutenção, além de oferecer confiabilidade, o que caracteriza garantia de operacionalidade dos equipamentos, eleva também a produtividade, além de contribuir no processo de uma superioridade contínua da produção. Isso, consequentemente, acaba gerando impacto direto no resultado financeiro da empresa. Se examinar cuidadosamente aquelas palavras de Fogliato e de Kardec e Nascif, infere-se que a manutenção encontrase de fato, em evidência no planejamento estratégico da empresa.

No contexto acadêmico, o trabalho visa contribuir como fonte de futuras pesquisas e desenvolvimento para soluções na área da gestão de manutenção, mais especificamente no desenvolvimento do plano anual de manutenção preventiva de equipamentos de 


\section{DIGITAL ENG}

Semana Online Científica de Engenharia

25 a 27 de Outubro de 2021

cozinhas industriais. Este também traz uma contribuição importante para os autores, já que a análise será feita através de um estudo de caso de uma empresa real e em operação offshore, com isto os autores terão a experiência de estudar toda a problemática operacional e desenvolver a melhor estratégia cabível visando além da solução a melhor forma de contornar os gargalos presentes no processo, pondo em prática todo conhecimento adquirido no processo acadêmico do curso de engenharia de produção.

O presente trabalho visa revisar a bibliografia relativa à manutenção preventiva $\mathrm{e}$ apresentar uma visão geral acerca do tema, expondo os principais conceitos, sua importância e histórico, analisar a efetividade do atual plano anual de manutenção preventiva da cozinha e identificar os pontos de melhoria do mesmo.

\section{METODOLOGIA}

O início do estudo foi executado com a formação teórica sobre o tema, iniciandose por uma pesquisa bibliográfica e análise preliminar sobre o tema como fonte de pesquisa secundária, objetivando efetivar um estudo de caso do plano anual de manutenção preventiva dos equipamentos da cozinha.

A metodologia usada para o desenvolvimento do trabalho, foi o estudo de caso onde se realizou um levantamento de dados perante o inventário das máquinas, a matriz de criticidade dos equipamentos e o plano de manutenção preventiva. Paralelo à pesquisa, foram utilizados métodos comparativos com o objetivo de avaliar se os procedimentos utilizados pela empresa para manutenção e prevenção, se compara aos recomendados pelo manual de fabricante dos equipamentos.

\section{RESULTADOS E DISCUSSÕES}

Os resultados obtidos com o levantamento de dados é de que há a necessidade da implantação de um software de gestão, para auxiliar na estratégia de manutenção 


\section{DIGITAL ENG}

Semana Online Científica de Engenharia

25 a 27 de Outubro de 2021

preventiva da empresa, tendo assim uma maior visibilidade acerca das necessidades de cada equipamento, de ter, como por exemplo, aviso das datas certas de manutenção que cada equipamento deve ter, com suas respectivas O.S diante às informações que alimentam o software. Também é indicada a implantação de medição de Backlog por unidade operacional e geral do setor, é um indicador que mede o acúmulo de atividades pendentes de finalização. É muito importante pois evidencia em quais aspectos a equipe deve focar e em quanto tempo a atividade precisa ser realizada.

Apesar de alguns pontos de melhorias detectados, num geral a empresa apresenta um bom e respeitado plano de manutenção, com uma boa gestão e participação ativa de seus colaboradores.

\section{CONSIDERAÇÕES FINAIS}

O desenvolvimento do presente estudo possibilitou aprofundar os conhecimentos, assim estudando o inventário da empresa, também conseguiu-se estudar os manuais de instruções para entender o processo de cada máquina.

A partir da autorização para a implantação das mudanças pela direção da empresa, acredita-se em uma agilidade maior no processo produtivo, redução de horas paradas por manutenção corretiva, atendimento dos prazos de entrega dos produtos e desta forma gerando mais lucro para a empresa.

\section{REFERÊNCIAS}

Fogliato, F. Confiabilidade e Manutenção Industrial. Rio de Janeiro: Grupo GEN, $2009.9788595154933 . \quad$ Disponível em: https://integrada.minhabiblioteca.com.br/\#/books/9788595154933/. Acesso em: 06 Apr 2021.

KARDEC, Allan; NASCIF, Júlio. Manutenção - Função Estratégica. $4^{\mathrm{a}}$ Edição: Rio de Janeiro: Qualitymark, 2013. 